\title{
IMPORTANCIA DE LAS HUMANIDADES EN ODONTOESTOMATOLOGÍA
}

\author{
Cristina Alicia Deangelillo*
}

\begin{abstract}
Resumen: Para ser auténtica, la educación debe sentar sus bases en valores; no debe ser un simple adiestramiento teórico-práctico. Esto implica que, también en odontología, debemos preparar personas reflexivas ante las consecuencias de sus acciones. No sólo formar técnicos, sino profesionales con amplios conocimientos científicos relacionados con los valores de la persona. Una medida esencial es incluir a la bioética en el currículo de grado en odontoestomatología.
\end{abstract}

Palabras clave: educación, valores, bioética

\section{IMPORTANCE OF HUMANITIES IN ORAL HEALTH CURRICULA}

\begin{abstract}
In order to be authentic, education must be based on values, not only a training in practice and theoretical aspects. This implies that, for dentistry training as well, we must prepare persons who reflect upon the consequences of their actions. We must train not only technicians, but professionals with broad scientific knowledge in relation with personal values. The introduction of bioethics in oral health curricula is an essential measure.
\end{abstract}

Key words: education, values, bioethics

\section{IMPORTANCIA DAS HUMANIDADES NA ODONTOESTOMATOLOGIA}

Resumo: Para ser autêntica, a educação deve assentar suas bases em valores. Não deve ser um simples adestramento téórico-prático. Isto implica que, também em odontologia, devemos preparar pessoas reflexivas ante as consequências de suas ações. Não somente formar técnicos, mas profissionais com amplos conhecimentos científicos relacionados com os valores da pessoa. Uma medida essencial é incluir a bioética no currículo de graduação em odontoestomatologia

Palavras chave: Educação, valores, bioética

Coordinadora del Área de Bioética del Círculo Argentino de Odontología. Argentina Correspondencia: cadan@intramed.net 


\section{Introducción}

En los comienzos del siglo XXI -siglo de tecnología y desmoralización- será necesario que nos comprometamos desde esta nueva disciplina, la bioética. Ella ha de fusionarse con el saber odontoestomatológico que, después de treinta años, comienza a iluminar con otra luz el actuar de la profesión.

Es urgente comenzar a trabajar para incorporar la bioética en nuestras aulas. Ello implica un cambio en el conocimiento de la ciencia odontoestomatológica actual para situarla desde una reflexión profunda.

Si quiere constituir un auténtico proceso de formación, la educación debe fundar sus bases en valores y no en un simple adiestramiento teórico-práctico. Esto significa que debemos preparar personas con criterio y reflexivas ante las consecuencias de sus acciones.

\section{Proceso enseñanza-aprendizaje}

Las antiguas ciencias médicas resaltaban el sentido integral del hombre; el racionalismo de la Edad Moderna, sin embargo, insistió en dividir al ser humano en distintos compartimientos sin interrelaciones.

Hoy, en una época de grandes cambios sociales, se debe reconocer aquel pensamiento integral y hacer posible el reencuentro del camino marcado por la ciencia clásica. Éste debe reflejarse en la formación de los profesionales de la salud, quienes no sólo deberán conocer su disciplina y ser excelentes técnicos, sino, también, usar un pensamiento crítico para resolver las complejas situaciones en la práctica diaria.

Comprendemos que la educación es un proceso de formación basado en valores. Para que llegue a ser eficiente y no un simple entrena- miento, será necesario orientarla hacia el "aprender a ser" (socioafectivo), "aprender a aplicar" (procedimental) y "aprender a aprender" (cognitivo).

En todo proceso enseñanza-aprendizaje los estudiantes toman como modelo las actitudes que observan en sus formadores; desde esta perspectiva, es nuestra responsabilidad enseñar a cuidar la vida, como valor primario. Habrá que implementar un nuevo enfoque educativo en la odontoestomatología, dirigido hacia una correcta técnica (procedimientos), basado en un amplio conocimiento científico (conceptos), sin olvidar los valores de las personas (actitudes).

Las humanidades médico-odontológicas serán aquellas disciplinas que tendrán como objetivo la comprensión valórica de los pacientes -respetando su dignidad e integridad, y actuando con solidaridad-, mejorando así toda relación y comunicación en busca de excelencia y equidad.

Son muy pocas las facultades de odontología -al menos en Argentina- que han incorporado las humanidades como asignatura en las carreras de grado o, mejor, un departamento de humanidades. Quizás sea esto un reflejo del desinterés entre los profesionales de la ciencia odontológica. Sólo en algunos programas de grado, en la asignatura de Odontología Legal, se presenta la Historia de la Odontología y se menciona la deontología al hacer referencia al Código de Ética en el ejercicio profesional.

En un espíritu de búsqueda constante (de la verdad, belleza, justicia y salud como un bien), el primer libro que debemos entregar al educando debe ser un Código de Ética, cuyo objetivo será integrar la comprensión, amabilidad, integridad y caridad al ejercicio odontológico: una guía para la ética odontológica, reafirmando los valores en beneficio del paciente, pero siempre desde su autodeterminación. 


\section{Mirada bioética en odontoestomatología}

A lo largo de la historia, se ha reconocido a la boca una gran importancia en la vida humana, puesto que tanto el hambre como el amor se centralizan en ella. Según Ramón Torres, con marcada trayectoria en ortodoncia, “...el hambre será saciado por intermedio de la boca y el hombre no es poseedor de órgano alguno capaz de reemplazarla naturalmente en ese menester de la vida (...) el amor tendrá que expresarse de algún modo por su intermedio como expresión erótica en equilibrio. El gesto, la palabra, el beso serán otras tantas maneras de manifestar ese sentimiento que acerca a los hombres, pero también de acuerdo con su particular sentir(1)".

No se ha puesto suficientemente atención en la boca, con un criterio biológico y humano, para llegar a comprenderla como parte de un todo. El hombre debe ser percibido en su totalidad, como persona, en su relación con el medio, con sus funciones y acciones. Percibir la boca sólo con un criterio morfológico, marcado por la especialización, hace que nos olvidemos de la totalidad que constituye la experiencia humana(1).

La salud es uno de los temas prioritarios en la sociedad, transformándose en un derecho fundamental si consideramos la protección de la persona. La enfermedad (desequilibrio psicofísicosocial) implica la pérdida o alteración de una función vital y se relaciona con todo el individuo, en conjunto con su medio social y natural, como una unidad que abarca no sólo lo anatómico, sino también la historia y naturaleza de la enfermedad(2).

La ciencia odontológica constituye más que un diagnóstico o tratamiento de enfermedades bucodentales. Ello por actuar en una cavidad orgánica, con funciones generales y específicas, que permite la comunicación de la persona con el medio. La salud bucodental redunda en la salud general, por lo tanto, sus objetivos deben estar orientados hacia su conservación, en busca de una mejor calidad de vida y con los principios de integridad y dignidad de la persona. Para ello se necesita de distintos grupos de acciones sanitarias:

- Promoción (función educadora).

- Prevención primaria (controles y exámenes periódicos) y secundaria (impedir la extensión de la enfermedad e indicar el tratamiento adecuado).

- Recuperación (proceso funcional para que el enfermo recobre la actividad del órgano afectado).

- Rehabilitación (proceso para devolver al enfermo la actividad funcional).

Teniendo en cuenta que todo acto odontoestomatológico es no sólo una operación o conjunto de operaciones concretas, sino el encuentro consciente y confiado entre profesional y paciente en busca de la prevención, el diagnóstico, el pronóstico y el tratamiento o la rehabilitación, sería prudente preguntarnos:

- ¿Por qué no se advierte la relación riesgobeneficio? ¿Por ignorancia o por mala fe?

- ¿Una actitud profesional se manifiesta no haciendo lo que se debe hacer cuando se puede hacer algo pero bien?

- ¿Existe la intención de hacer un buen diagnóstico, un buen pronóstico y un buen plan de tratamiento?

- ¿Se aceptan las decisiones de nuestros pacientes?

- ¿Se tiene en cuenta en cada especialidad los riesgos que se pueden presentar?

Nuestro acto profesional es un acto complejo, es un acto moral. No basta sólo lo científico, 
sino que se debe buscar un propósito y comunicar las consecuencias para llegar a una decisión terapéutica. En esta complejidad van a intervenir elementos como la deliberación y la elección del paciente. Será nuestra actitud interior la que considerará los pro y los contra de nuestro acto profesional, llevándonos a una profunda reflexión desde el núcleo de la persona(3).

\section{Conclusión}

Para hablar de salud desde un enfoque integral es necesario pensar que, en odontoestoma- tología, no se trata de formar técnicos, sino profesionales con amplios conocimientos científicos relacionados con los valores de la persona.

Es preciso que nos comprometamos para que en nuestras aulas se enseñen las humanidades y, de esta manera, no sólo llegar a conocer y hacer, sino también aprender a ser sujetos íntegros en el marco de la cultura, aprender a adoptar decisiones desde el punto de vista ético, cuando logremos detectar los dilemas con mayor idoneidad.

\section{Referencias}

1. Torres R. Biología de la boca. Estructura y Función. Buenos Aires: Editorial Médica Panamericana; 1973.

2. Weingarten C. Responsabilidad por prestaciones odontológicas. Buenos Aires: Editorial Astrea; 1997.

3. Deangelillo CA. Bioética y Odontología. El Cooperador Dental 2003; 288: 15-18.

Recibido: 03 de enero de 2006

Aceptado: 31 de enero de 2006 